Sigma Teknika, Vol.1, No.2 : 122-132

November 2018

E-ISSN 2599-0616

P ISSN 2614-5979

\title{
ANALISA PENGUJIAN RESISTANSI TEGANGAN TEMBUS PADA OLI TRANSFORMATOR 5.000 KVA DI PLTMG PANBIL
}

\author{
Ahmad Rezki ${ }^{[1]}$, Toni Kusuma Wijaya, ${ }^{[2]}$, M.Irsyam, ${ }^{[3]}$ \\ Program Studi Teknik Elektro, Universitas Riau Kepulauan Batam ${ }^{1,2,3}$ \\ tonikusuma26@yahoo.co.id
}

\begin{abstract}
Abstrak
Pada pembangkit listrik tenaga mesin gas (PLTMG) panbil memerlukan tenaga listrik untuk pemakaian internal didalam pusat pembangkit listrik sendiri dan untuk disalurkan ke konsumen yang ada di kawasan industry panbil. System kelistrikan tentunya memerlukan peralatan yang layak pakai (memenuhi standard). Pengukuran tahanan (resistansi) oli transformator pada PLTMG panbil tentunya harus memenuhi standard agar dapat melindungi system dan komponen yang ada didalam transformator tersebut. Perencanaan pengukuran tahanan isolasi transformator dilakukan secara berkala, berdasarkan pada acuan standard SPLN29-1 : 1992. Methode IEC 156 dan IEC 296 dimana standart untuk melakukan pengujian pada tahanan oli transformator tersebut adalah satu tahun sekali, Apabila terdapat tahanan isolasi transformator yang sudah mendekati standart, oli transformator tersebut harus segera dilakukan langkah pemurnian (furifying) oli transformator tersebut, pemurnian oli tersebut bertujuan untuk meningkatkan tahanan isolasi cair yang ada didalam transformator. Dalam penelitian ini dilakukan pengukuran tahanan oli transformator, pengukuran oli transformator tersebut dilakukan sebanyak dua kali pengukuran, yaitu pengukuran sebelum dan sesudah dimurnikan, dimana menurut standartd SPLN29-1 : 1992. Methode IEC 156 dan IEC 296 sebelum dilakukan pengukuran nilai tahanan oli $\leq 30 \mathrm{KV} / 2,5 \mathrm{MM}$ dan sesudah dimurnikakan $\leq 50 K V / 2,5 M M$. Penentuan pemurnian oli transformator telah selesai atau belum disesuaikan menurut standard yang telah dijelaskan diatas, nilai tahanan oli transformator sebelum dilakukan dilakukan pemurnian oli adalah senilai 30,7KV/2,5MM dan setelah pemurnian sebesar 67,133KV/2,5MM. dan setelah dianalisa untuk langkah meningkatkan tahanan oli transformator tersebut sudah benar karena nilai tahanan sebelum dilakukan pemurnian sudah sangat mendekati standrat, dan setelah dilakukan pemurnian oli transformator, tahanan oli transformator tersebut sudah memenuhi standard dan sudah layak operasi karena keadaan oli transformator sudah dalam keadaan bagus.

Kata kunci: $\quad$ pengukuran tahanan, standard yang dipakai, hasil pengukuran.
\end{abstract}

\subsection{Latar Belakang}

Dalam sebuah sistem tenaga listrik mengandung resiko yang besar terjadi gangguan peralatan listrik yang dapat membahayakan manusia maupun peralatan itu sendiri. Berdasarkan data dari dinas kebakaran DKI pada tanggal 24 juli 2013 telah terjadi kebakaran disalah satu gedung plaza UOB yang berlokasi di jalan Ah.Thamrin, Jakarta pusat. Kasus terjadinya kebakaran ini disebabkan adanya hubungan singkat pada transformator dimana isolasi komponen transformator tersebut sudah jelek, dan nilai tahanan oli transformatornya sudah dibawah standart yang berlaku, dimana di Indonesia memakai standart SPLN291 : 1992. Methode IEC 156 dan IEC 296.

Pada PLTMG (Pembangkit Listrik Tenaga Mesin Gas) panbil memiliki unit pembangkitan dengan kapasitas daya sebesar 27 MW. Pada PLTMG panbil memiliki transformator 
Sigma Teknika, Vol.1, No.2 : 122-132

November 2018

E-ISSN 2599-0616

P ISSN 2614-5979

step up sebanyak 8 buah transformator masing-masing transformator 5.000 KVA, transformator distribusi sebanyak 43 buah, dan transformator auxiliary sebanyak 2 buah. Tenaga listrik yang dihasilkan PLTMG panbil di distribusikan untuk kawasan industry yang ada dikawasan panbil industrial estate. Selain keandalan kuantitas, keandalan kualitas komponen yang dipakai menjadi salah satu hal yang sangat penting dalam system kelistrikan, apakah masih layak pakai, atau saatnya dilakukan perawatan, ataupun sudah saatnya dilakukan penggantian pada komponen tersebut. Kondisi oli transformator yang kotor akan mengganggu kinerja transformator tersebut, sehingga perlu dilakukan test tegangan tegangan tembus oli transfotmator, dan selanjutnya dilakukan langkah pemurnian dengan proses Furifying Treatment Oil Transformator, proses pemurnian oli transformator dimasukkan dalam salah satu aktifitas perawatan

(maintenance) transformator panbil. Dalam system perawatan oli transformator ini, pengujian tahanan oli transformator adalah tolak ukur sebelum dilakukan proses pemurnian, apakah sudah saatnya dilakukan langkah pemurnian pada oli tersebut atau belum.

\subsection{Rumusan Masalah}

Dari latar belakang yang telah dijelaskan penulis diatas, rumusan masalah yang bisa penulis ambil adalah:

1. Berapa nilai tahanan tegangan tembus oli transformator menurut SPLN29-1 : 1992.
Methode IEC 156 dan IEC 296 sebelum dilakukan pemurnian.?

2. Berapa nilai tahanan tegangan tembus oli transformator menurut SPLN29-1 : 1992. Methode IEC 156 dan IEC 296 setelah dilakukan pemurnian.?

\subsection{Tujuan Penelitian}

Adapun tujuan penelitian dari pembahasan pemurnian oli transformator pada PLTMG Panbil adalah:

1. Menentukan nilai tahanan tegangan tembus oli transformator sebelum dilakukan langkah pemurnian menurut SPLN29-1 : 1992. Methode IEC 156 dan IEC 296.

2. Menentukan nilai tahanan tegangan tembus oli transformator setelah dilakukan langkah pemurnian menurut SPLN29-1 : 1992. Methode IEC 156 dan IEC 296.

\subsection{Batasan Masalah}

Agar pembahasan menjadi terarah dan tidak menyimpang dari topik, maka dalam penulisan tugas akhir ini penulis membatasi permasalahan yang akan dibahas yaitu

1. Pembahasan hanya pada perawatan oli transformator.

2. Pembahasan dan perhitungan menggunakan pendekatan data sheet dan menggunakan data pengukuran lapangan.

3. Pembahasan tegangan tembus oli transformator hanya 
Sigma Teknika, Vol.1, No.2 : 122-132

November 2018

E-ISSN 2599-0616

P ISSN 2614-5979

membahas tegangan tembus oli transformator 5.000 KVA.

\subsection{Transformator}

Transformator adalah suatu peralatan listrik yang befungsi menyalurkan tenaga/daya listrik dari tegangan tinggi ke tegangan rendah atau tegangan rendah ke tegangan tinggi tergantung kebutuhan yang kita inginkan dengan frekuensi sama.

Prinsip kerja dari transformator yaitu arus listrik bolak-balik yang mengalir mengelilingi suatu inti besi akan berubah menjadi magnit dan apabila magnit tersebut dikelilingi oleh suatu belitan maka pada kedua ujung belitan tersebut akan terjadi beda tegangan, akibatnya pada sisi primer terjadi induksi, Sisi sekunder menerimagaris gaya magnet dari sisi primer yang jumlahnya berubah-ubah pula, Maka di sisi sekunder juga timbul induksi, akibatnya antara dua ujung terdapat beda tegangan.

\subsection{Jenis-Jenis Transformator dan Penggunaannya}

Ada beberapa jenis transformator yang dikenal dan digunakan secara luas di masyarakat, diantaranya adalah:

1. Transformator Daya

2. Transformator Distribusi

3. Transformator Tegangan (Potensial Transformator)

4. Transformator Arus (Current Transformator)

\subsection{Dielektrik Cair}

Kekuatan dielektrik cair merupakan ukuran kemampuan suatu material untuk bisa menahan tegangan tinggi tanpa berakibat terjadinya kegagalan dielektrik. Kekuatan dielektrik cair tergantung pada sifat atom dan molekul cairan itu sendiri, material dari elektroda, suhu, jenis tegangan yang diberikan, gas yang terdapat dalam cairan, dan sebagainya yang dapat merubah sifat molekul cairan. Dalam isolasi cair kekuatan dielektriik setara dengan tegangan yang terjadi. Menurut hukum Paschen's, kekuatan dielektrik cair berkisar antara $107 \mathrm{~V} / \mathrm{cm}$.

\subsection{Minyak Transformator Sebagai Bahan Isolasi \\ Minyak transformator sering} digunakan dalam peralatan tegangan tinggi. Minyak transformator merupakan jenis minyak organik. Minyak transformator hampir tidak berwarna yang tersusun dari senyawa hidrokarbon yang terdiri dari paraffin, iso-parafin, naphthalene dan aromatic. Beberapa pengotor mempunyai sifat korosif terhadap material isolasi padat dan bagian-bagian konduktor pada transformator. Lumpur yang menumpuk pada inti transformator.

\subsection{Sifat-Sifat Dielektrik Cair}

Dielektrik cair adalah suatu bahan yang memiliki daya hantar arus yang sangat kecil atau bahkan hampir tidak ada. Adapun sifat-sifat dielektrik cair adalah sebagai berikut:

1. Sifat Fisika

2. Sifat Kelistrikan

3. Kekentalan (Viskositas)

\subsection{Penyebab Turunnya Tahanan (Tegangan Tembus) Oil Transformator}


Sigma Teknika, Vol.1, No.2 : 122-132

November 2018

E-ISSN 2599-0616

P ISSN 2614-5979

Perlu kita ketahui, ada beberapa hal yang menyababkan kerusakan pada oli transformator, berikut adalah contoh penyebab kerusakan pada oli transformator:

1. Drum penyimpanan yang tidak baik, sehingga akan menyebabkan terjadi kotoran seperti karatan dan sebagainya.

2. Transformator beroperasi dalam keadaan berbeban maksimum secara terus menerus, sehingga temperature minyak menjadi tinggi dan akan mengakibatkan terjadinya uap air.

3. Pengoperasian transformator yang tidak konsisten.

4. Silicagel yang sudah rusak.

5. Minyak mengandung unsur karbon dan asam yang banyak $(\mathrm{CO}, \mathrm{CO} 2, \mathrm{CH} 4, \mathrm{C} 2 \mathrm{H} 4, \mathrm{C} 2 \mathrm{H} 6)$

6. Usia oli transformator sudah tua.

7. Tahanan isolasi transformator sudah dibawah standar minimal yaitu $30 \mathrm{KV} / 2.5 \mathrm{~mm}$.

\subsection{Teori Kegagalan Dielektrik Cair \\ Pada isolasi minyak}

transformator akan berubah jika terjadi ketidak murnian di dalamnya. Hal ini akan mempercepat terjadinya proses kegagalan. Faktor-faktor yang mempengaruhi kegagalan isolasi antara lain adanya partikel padat, uap air dan gelembung gas. Teori kegagalan isolasi yang terjadi pada minyak transformator dibagi menjadi empat jenis sebagai berikut:

1. Teori kegagalan elektronik.

2. Teori kegagalan karena adanya gelembung gas.

3. Teori kegagalan partikel padat

4. Teori kegagalan bola cair

\subsection{Pemurnian Oli \\ Transformator (Treatment Oil Transformator)}

Agar transformator selalu beroperasi dengan baik, transformator sebaiknya selalu dirawat dengan teratur. Harus ada perhatian khusus jika transformator beroperasi dengan beban penuh/atau di kondisi-kondisi tertentu yang berbahaya. Sebelum dilakukan pekerjaan, transformator harus dilepaskan dari rangkaian eksternal dan harus ditanahkan (ground) dengan baik (buang tegangan sisa operasi transformator), agar tidak terjadi hal-hal yang tidak diinginkan.

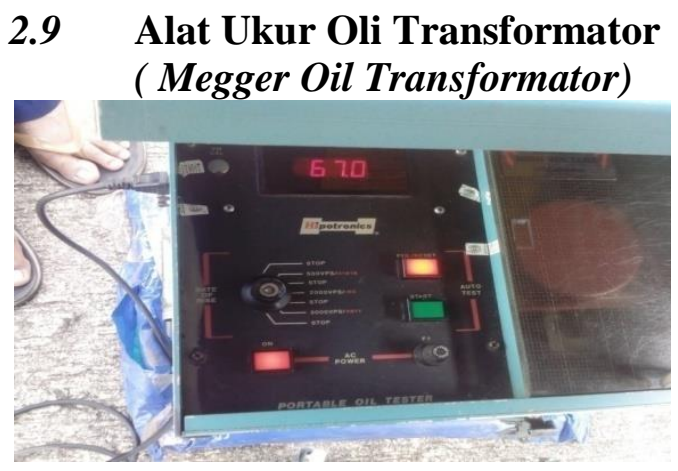

Didalam transformator daya atau transformator distribusi $20 \mathrm{KV}$ (tegangan menengah) terdapat oli yang berfungsi memisahkan kumparan primer dan kumparan sekunder agar tidak terjadi tegangan tembus, oli transformator ini memiliki tingkat isolasi yang lebih tinggi dari pada udara bebas. Salah satu parameter yang dapat menunjukkan baik atau buruknya tahanan oli adalah tegangan tembusnya. 
Sigma Teknika, Vol.1, No.2 : 122-132

November 2018

E-ISSN 2599-0616

P ISSN 2614-5979

Dari gambar diatas, untuk mencari hasil tegangan tembus per $1 \mathrm{KV}$ dapat dirumuskan:

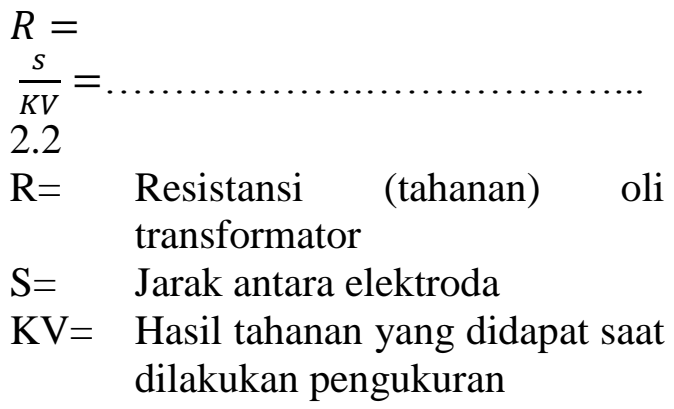

\subsection{Profil Perusahaan}

Seiring dengan perkembangan kawasan industri Panbil Industrial Estate, Managemen Panbil Group mulai menanamkan investasi pembangkit listrik untuk kebutuhan internal kawasan. Maka pada tahun 2006, Panbil Group mengambil alih pembangkit listrik yang sebelumnya dikelola PT. Gokindo Daya Bersama.

Selanjutnya Panbil Group menjadikan pembangkit listrik menjadi salah satu divisi di dalam tubuh PT. Panbil Utilitas Sentosa yang merupakan anak perusahaan dari Panbil Group. PT. Panbil Utilitas Sentosa memiliki beberapa divisi diantaranya : Divisi Power Plant (Pembangkit Listrik), WTP (Water Threatment Plant) serta WWTP (Waste Water Threatment Plant).

Dengan perkembangan kebutuhan listrik di kawasan Panbil Industrial Estate, PT. Panbil Utilitas Sentosa dituntut untuk lebih menjaga kualitas maupun kuantitas listrik yang di distribusikan ke tenant. Untuk saat ini PT. Panbil Utilitas Sentosa memiliki kapasitas pembangkit sebesar 23 MegaWatt yang terdiri dari 5 unit pembangkit PLTMG dan 2 unit pembangkit PLTD.

\subsection{Produk Pemasaran}

Bidang usaha PT. Panbil Utilitas Sentosa meliputi supply listrik, air bersih maupun pengelolaan air kotor yang terdapat di kawasan Panbil Industrial Estate. Untuk divisi pembangkit listrik sendiri, PT. Panbil Utilitas Sentosa bekerja sama dengan PLN dan masuk ke dalam sistem interkoneksi PLN area Batam.

Selain fokus untuk memenuhi kebutuhan listrik kawasan Panbil Industrial Estate, PT. Panbil Utilitas Sentosa juga mensupply listrik untuk PLN dengan kapasitas yang telah disepakati sesuai dengan kontrak kerja.

\subsection{Visi dan Misi Perusahaan}

Bagi suatu organisasi visi dan misi memiliki peranan yang penting dalam menentukan arah kebijakan dan karakteristik organisasi tersebut. Adapun visi dan misi PT. PanbilUtilitas Sentosa adalah sebagai berikut:

Visi : Visi PT Panbil Utilitas Sentosa adalah menjadi pembangkit yang handal, aman, dan ramah lingkungan bagi kota batam.

Misi : PT Panbil Utilitas Sentosa sebagai perusahaan bidang supply energi listrik mempunyai komitmen untuk menyediakan supply listrik yang berkesinambungan dan mempunyai kualitas terjamin dan sesuai standar yang berlaku dan berketetapan untuk terus memperbaiki kinerjanya sehingga dapat mencapai standar internasional dan menjadi kompetitor terkemuka dalam dunia industri nasional yang sejenis pada umumnya. 
Sigma Teknika, Vol.1, No.2 : 122-132

November 2018

E-ISSN 2599-0616

P ISSN 2614-5979

\subsection{Alir Diagram Metodologi} Penelitian

Pada penelitian Analisa Pengujian Tegangan Tembus Oli Transformator 5.000 KVA Panbil dimulai dari alir diagram Metodologi Penelitian seperti dibawah ini :

Tabel 4.1 Alir Diagram Penelitian

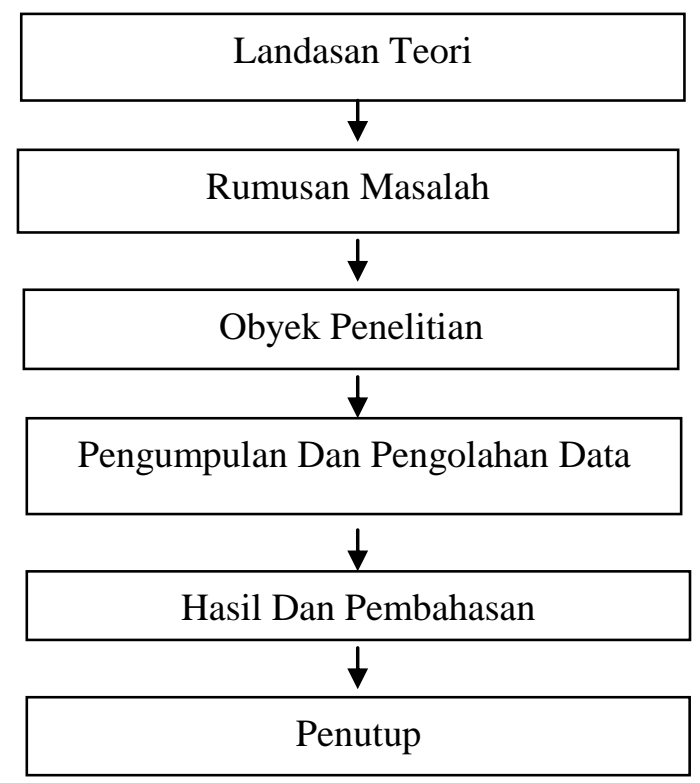

\subsection{Rumusan Masalah}

Pada tahap ini dilakukan perumusan masalah agar penelitian lebih terarah dan mencapai hasil yang maksimal serta sesuai yang diharapkan. Adapun rumusan masalah yang telah ditentukan yaitu seperti pada bab I (sub bab 1.2)

\subsection{Landasan Teori}

Dalam penelitian Analisa Analisa Pengujian Tegangan Tembus Oli Transformator 5.000 KVA Panbil menggunakan beberapa landasan teori, diantaranya :

1. Transformator.
2. Cara kerja dan fungsi tiap-tiap bagian transformator.

3. Jenis-jenis transformator dan penggunaannya.

4. Pengetesan resistansi (tahanan) tegangan tembus oli transformator $5.000 \mathrm{KVA}$ di PLTD PANBIL.

\subsection{Obyek Penelitian}

Penelitian Analisa Pengujian Resistansi Tegangan Tembus Pada Oli Transformator 5.000 KVA Di PLTMG Panbil dilakukan pada Power Plant Panbil PT. Panbil Utilitas Sentosa yang berada di kawasan Panbil Industrial Estate Jln. Ahmad Yani, Muka Kuning, Batam.

Obyek penelitian yaitu menentukan hasil pengukuran resistansi pada oli transformator 5.000 KVA layak atau tidaknya oli transformator untuk dioperasikan, yang berfungsi untuk menjaga kelancaran operasional transformator dan kualitas listrik untuk dipakai sendiri dan untuk disalurkan kepada konsumen yang ada di kawasan Panbil Industrial Estate.

\subsection{Pengumpulan Pengolahan Data}

Dan

Data-data yang diperlukan dalam penelitian Analisa Pengujian Resistansi Tegangan Tembus Oli Transformator 5.000 KVA di PLTMG Panbil adalah sebagai berukut:

1. Flowchat penulisan.

2. Data Transformator.

3. data pengukuran tahanan oli transformator sebelum dilakukan proses pemurnian. 
4. data pengukuran tahanan oli transformator setelah dilakukan proses pemurnian.

Adapun cara menghitung rata-rata data yang didapat dari pengukuran dari lapangan, menggunakan rumuskan persamaan 2.1

$$
\begin{aligned}
& x=\frac{\mathrm{X}^{1}+\mathrm{X}^{2}+\mathrm{X}^{3} \ldots+\mathrm{Xn}}{\mathrm{n}} \\
& x=\text { rata-rata hitung } \\
& x i=\text { nilai sampel ke- } i \\
& n=\text { jumlah sampel }
\end{aligned}
$$

\subsection{Hasil Dan Pembahasan}

Setelah mengetahui parameterparameter yang diperlukan, dalam bab ini penulis melakukan Analisa Pengujian Tegangan Tembus Oli Transformator 5.000 KVA di PLTMG Panbil dengan langkah-langkah sebagai berikut :

1. Mengukur tahanan tegangan tembus oli transformator sebelum pemurnian.

2. Mengukur tahanan tegangan tembus oli transformator setelah pemurnian.

3. Membandingkan Nilai Tahanan Yang Didapat Dengan Standart Yang SPLN-IEC NO 196 \& 256

\subsection{Penutup}

Pada tahap akhir ini, penulis mengambil kesimpulan dari hasil penelitian Analisa pengujian tegangan tembus oli transformator 5.000 KVA di PLTMG Panbil. Setelah menyimpulkan hasil penelitian, kemudian melakukan evaluasi keseluruhan sehingga menghasilkan saran-saran untuk meningkatkan perhatian husus untuk memperhatikan keadaan oli transformator kedepannya.

\subsection{Flowchart Penelitian}

Agar mudah dipahami dan dimengerti, berikut adalah flowchart penelitian laporan ini.

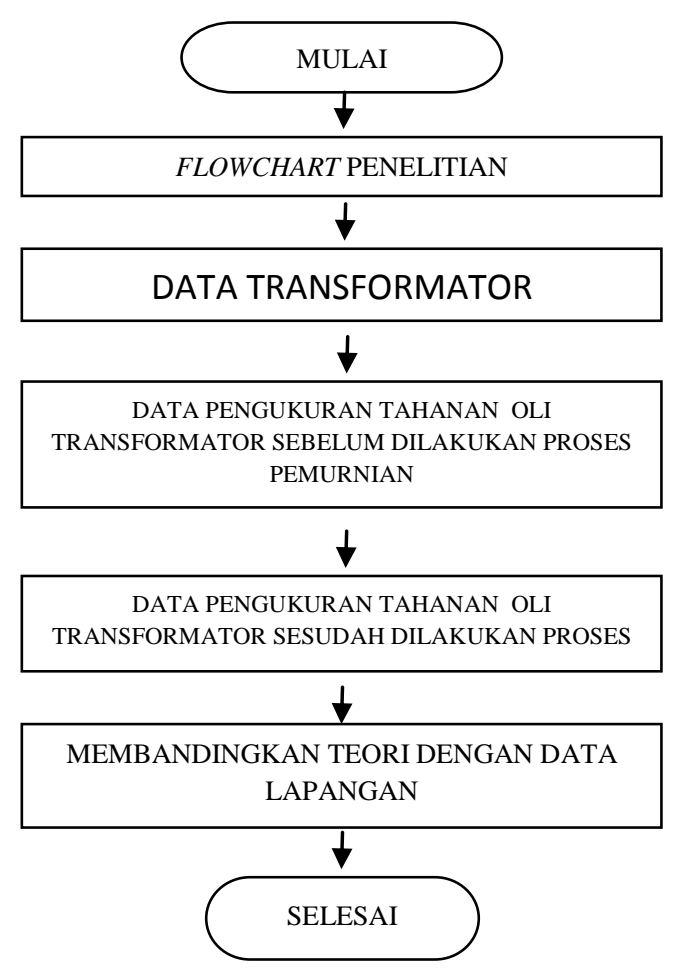

Gambar 5.1 Flowcart penelitian

\subsection{Data Transformsator}

Transformator yang dianalisa pada skripsi ini adalah transformator yang berkapasitas 5.000 KVA ber merk UNINDO. Berikut adalah tabel data transformator Tabel 5.1 Data Trnsformator 
Sigma Teknika, Vol.1, No.2 : 122-132

November 2018

E-ISSN 2599-0616

P ISSN 2614-5979

\begin{tabular}{|c|c|c|c|c|}
\hline $\begin{array}{l}\mathrm{N} \\
\mathrm{o} \\
\mathrm{T} \\
\mathrm{es} \\
\mathrm{t}\end{array}$ & $\begin{array}{l}\text { Tega } \\
\text { ngan } \\
\text { Tem } \\
\text { bus } \\
\text { (KV } \\
\text { ) }\end{array}$ & $\begin{array}{l}\text { Wak } \\
\text { tu } \\
\text { (t) }\end{array}$ & $\begin{array}{l}\text { Hasil } \\
\text { Rata- } \\
\text { Rata } \\
\text { Tegang } \\
\text { an } \\
\text { Tembus } \\
(\mathrm{KV})\end{array}$ & $\begin{array}{l}\text { Ketera } \\
\text { ngan }\end{array}$ \\
\hline 1 & $\begin{array}{l}32,7 \\
\mathrm{KV} / \\
2,5 \\
\mathrm{MM}\end{array}$ & $\begin{array}{l}5 \\
\text { Men } \\
\text { it }\end{array}$ & \multirow{6}{*}{$\begin{array}{l}30,7 \\
\mathrm{KV} / 2,5 \\
\mathrm{MM} \\
(122,8 / \\
\mathrm{CM})\end{array}$} & \multirow{6}{*}{$\begin{array}{l}\text { Oli } \\
\text { transfo } \\
\text { rmator } \\
\text { sudah } \\
\text { mende } \\
\text { kati } \\
\text { standa } \\
\text { rt } \\
\text { IEC } \\
\text { SPLN. } \\
\text { Segera } \\
\text { di } \\
\text { murni } \\
\text { kan }\end{array}$} \\
\hline 2 & $\begin{array}{l}36,3 \\
\mathrm{KV} / \\
2,5 \\
\mathrm{MM}\end{array}$ & $\begin{array}{l}2 \\
\text { Men } \\
\text { it }\end{array}$ & & \\
\hline 3 & $\begin{array}{l}30,7 \\
\mathrm{KV} / \\
2,5 \\
\mathrm{MM}\end{array}$ & $\begin{array}{l}2 \\
\text { Men } \\
\text { it }\end{array}$ & & \\
\hline 4 & $\begin{array}{l}20,2 \\
\mathrm{KV} / \\
2,5 \\
\mathrm{MM}\end{array}$ & $\begin{array}{l}2 \\
\text { Men } \\
\text { it }\end{array}$ & & \\
\hline 5 & $\begin{array}{l}32,4 \\
\mathrm{KV} / \\
2,5 \\
\mathrm{MM} \\
\end{array}$ & $\begin{array}{l}2 \\
\text { Men } \\
\text { it }\end{array}$ & & \\
\hline 6 & $\begin{array}{l}31,9 \\
\mathrm{KV} / \\
2,5 \\
\mathrm{MM}\end{array}$ & $\begin{array}{l}2 \\
\text { Men } \\
\text { it }\end{array}$ & & \\
\hline
\end{tabular}

Pengukuran tahanan oli transformator dilakukan minimum setahun sekali demi menjaga mutu oli transformator dan untuk menghindari terjadinya kerusakan pada komponen yang ada didalam transformator. Pengukuran sebelum dilakukan pemurnian oli transformator sangat penting dalam proses perawatan oli transformator, dimana pengukuran oli pada step pertama adalah sebagai tolak ukur untuk melanjutkan langkah perawatan apakah oli transformator tersebut sudah saatnya dilakukan pemurnian atau belum. Berikut adalah table pengukuran oli transformator sebelum dilakukan langkah pemurnian oli transformator.

Tabel 5.2 Data pengukuran tahanan oli trasformator sebelum dimurnikan

Data pengukuran pertama ini dilakukan untuk mengetahui nilai resistansi, dmana pengukuran pertama ini berfungsi untuk menentukan langkah berikutnya, dimana menurut standart SPLN-IEC no 196 dan 256 sudah sangat mendekati standart, menurut standart nilai tahanan oli transformator yaitu $30 \mathrm{KV} / 2,5 \mathrm{~mm}$ dan harus dilakukan langkah pemurnian pada oli.

\subsection{Data Pengukuran Oli Transformator Setelah Dilakukan Langkah Pemurnian Oli Transformator \\ Pengukuran tahanan oli} transformator setelah dilakukan

\begin{tabular}{|c|c|}
\hline $\begin{array}{c}\text { Merk } \\
\text { transformator }\end{array}$ & UNINDO \\
\hline $\begin{array}{c}\text { Daya } \\
\text { transformator }\end{array}$ & $5.000 \mathrm{KVA}$ \\
\hline Tahun pembuatan & 2009 \\
\hline Nomor seri & 85665 \\
\hline Tegangan (V) & $\begin{array}{c}20 \mathrm{kv} / \\
400 \sim 415 \\
\text { VOLT }\end{array}$ \\
\hline Phasa & 3 Phasa \\
\hline $\begin{array}{l}\text { Weighs core and } \\
\text { coil }\end{array}$ & $4700 \mathrm{KG}$ \\
\hline Weighs Oil & 2350 \\
\hline
\end{tabular}


Sigma Teknika, Vol.1, No.2 : 122-132

November 2018

E-ISSN 2599-0616

P ISSN 2614-5979

penting. dimana berfungsi untuk mengetahui apakah langkah pemurnian sudah selesai dilakukan atau belum.

Tabel 5.3 Data pengukuran tahanan oli trasformator sesudah dimurnikan

Sebelum dilakukan pengukuran yang kedua ini, sebelumnya dilakukan langkah pemurnian oli transformator yang berfungsi menaikkan tahanan (tegangan tembus) pada oli tersebut. Dan setelah dilakukan pengukuran pada oli tersebut, oli ini sudah layak dioperasikan kembali menurut standart SPLN-IEC no 195 dan 256, dimana menurut standart tersebut, standart oli transformator setelah dilakukan pemurnian tahanannya harus mencapai 50KV/2,5MM.

\subsection{Mengukur Tegangan Tembus Oli transformator Sebelum Pemurnian}

Dilihat dari standart SPLNIEC NO 196 DAN 256 sebelum dilakukan langkah pemurnian pertamatama kita harus melakukan pengukuran pada tahanan oli transformator tersebut apakah sudah saatnya dilakukan langkah pemurnian atau belum, data pengukuran diperlihatkan pada table 5.2. Dari data yang diperlihatkan dari table 5.2, tegangan tembus dapat dirata-ratakan dengan rumus persamaan 2.1.

$x=\frac{\mathrm{X}^{1}+\mathrm{X}^{2}+\mathrm{X}^{3} \ldots+\mathrm{Xn}}{\mathrm{n}}$

$x=\frac{32,7+36,3+30,7+20,2+32,4+31,9}{6}$

$X=33,7 \frac{K V}{2,5} M M$

Dengan data pengukuran yang

dilakukan sebanyak enam kali percobaan dilapangan dan setelah dirata-ratakan dari enam kali pengukuran tersebut didapatkan nilai tahanan 30,7 KV/2,5 MM. nilai tahanan ini sudah sangat mendekati standart SPLN-IEC NO 196 DAN 256 yaitu $30 \mathrm{KV} / 2,5 \mathrm{MM}$ dan harus segera

\begin{tabular}{|c|c|c|c|c|}
\hline $\begin{array}{l}\mathrm{N} \\
\mathrm{Te}\end{array}$ & $\begin{array}{c}\text { Tega } \\
\text { ngan } \\
\text { Temb } \\
\mathrm{u} \\
(\mathrm{KV})\end{array}$ & $\begin{array}{c}\text { Wak } \\
\text { tu } \\
(\mathrm{t})\end{array}$ & $\begin{array}{l}\text { Hasil } \\
\text { Rata- } \\
\text { Rata } \\
\text { Tegan } \\
\text { gan } \\
\text { Tembu } \\
\text { s } \\
(\mathrm{KV}) \\
\end{array}$ & $\begin{array}{l}\text { Keteran } \\
\text { gan }\end{array}$ \\
\hline 1 & $\begin{array}{l}67.0 \\
\mathrm{KV} / 2, \\
5 \\
\mathrm{MM}\end{array}$ & $\begin{array}{l}5 \\
\text { Men } \\
\text { it }\end{array}$ & \multirow{6}{*}{$\begin{array}{l}61,133 \\
\mathrm{KV} / 2, \\
5 \mathrm{MM} \\
(268,5 \\
3 \\
\mathrm{KV} / \mathrm{C} \\
\mathrm{M})\end{array}$} & \multirow{6}{*}{$\begin{array}{l}\text { Oli } \\
\text { transfor } \\
\text { mator } \\
\text { sudah } \\
\text { layak } \\
\text { diopera } \\
\text { sikan } \\
\text { sudah } \\
\text { diatas } \\
\text { standar } \\
t \text { IEC } \\
\text { SPLN } \\
30 \\
\text { KV/2,5 } \\
\text { MM }\end{array}$} \\
\hline 2 & $\begin{array}{l}67.0 \\
\mathrm{KV} / 2, \\
5 \\
\mathrm{MM}\end{array}$ & $\begin{array}{l}2 \\
\text { Men } \\
\text { it }\end{array}$ & & \\
\hline 3 & $\begin{array}{l}67.7 \\
\mathrm{KV} / 2, \\
5 \\
\mathrm{MM}\end{array}$ & $\begin{array}{l}2 \\
\text { Men } \\
\text { it }\end{array}$ & & \\
\hline 4 & $\begin{array}{l}66.8 \\
\mathrm{KV} / 2, \\
5 \\
\mathrm{MM}\end{array}$ & $\begin{array}{l}2 \\
\text { Men } \\
\text { it }\end{array}$ & & \\
\hline 5 & $\begin{array}{l}66.9 \\
\mathrm{KV} / 2, \\
5 \\
\mathrm{MM}\end{array}$ & $\begin{array}{l}2 \\
\text { Men } \\
\text { it }\end{array}$ & & \\
\hline 6 & $\begin{array}{l}67.4 \\
\mathrm{KV} / 2, \\
5 \\
\mathrm{MM} \\
\end{array}$ & $\begin{array}{l}2 \\
\text { Men } \\
\text { it }\end{array}$ & & \\
\hline
\end{tabular}

dilakukan langkah pemurnian pada oli transformator tersebut demi menjaga mutu dan kelancaran operasi transformator tersebut. 
Sigma Teknika, Vol.1, No.2 : 122-132

November 2018

E-ISSN 2599-0616

P ISSN 2614-5979

6.2 Mengukur

Tegangan Tembus Oli

Transformator Setelah

Pemurnian

Setelah dilakukan langkah pemurnian pada oli transformator, fungsi utama dilakukan pemurnian adalah untuk meningkatkan tahanan tegangan tembus pada oli transformator. Setelah dilakukan pemurnian oli transformator barulah dilakukan pengukuran tahanan kembali pada oli tersebut apakah sudah bisa dioperasikan kembali seperti normal atau belum, data pengukuran diperlihatkan pada tabel 5.3.

Dari data pengukuran tabel 5.3, tegangan tembus dapat dirata-ratakan dengan rumus persamaan 2.1.

$$
\begin{aligned}
& x=\frac{\mathrm{X}^{1}+\mathrm{X}^{2}+\mathrm{X}^{3} \ldots+\mathrm{Xn}}{\mathrm{n}} \\
& x=\frac{67,0+67,0+67,7+66,8+66,9+67,4}{6} \\
& x=61,133 \mathrm{KV}
\end{aligned}
$$

Setelah dilakukan pengukuran tahanan oli transformator pada oli tersebut sebanyak enam kali pengukuran, dan setelah dirata-rata kan dapat lah hasilnya $61,133 \mathrm{KV} / 2,5$ MM dan sudah dapat dioperasikan kembali seperti normal karena sudah memenuhi standart SPLN yaitu 50 $\mathrm{KV} / 2,5 \mathrm{MM}$.

6.3

$\begin{array}{lcr}\text { Membandingkan } & \text { Nilai } \\ \text { Tahanan } & \text { Yang } & \text { Didapat } \\ \text { Dengan } & \text { Standart } & \text { Yang } \\ \text { Berlaku } & & \end{array}$

Setelah dilakukan langkahlangkah menurut prosedur dan menurut standart SPLN-IEC NO 196 DAN 259, selanjutnya untuk membandingkan nilai yang didapat dengan nilai tahanan.

\subsubsection{Memebandingkan Nilai Tahanan Oli Tansformator Sebelum Dilakukan Langkah Pemurnian Dengan Standart SPLN-IEC NO $196 \& 256$}

Sebelum dilakukan langkah pemurnian oli transformator, pengukuran tahanan oli transformator adalah tolak ukur untuk melakukan langkah perawatan selanjutnya,

Dari hasil pengukuran dan dilihat dari standart, nilai tahanan oli transformator sudah saatnya dilakukan langkah pemurnian oli transformator. Dari nilai pengukuran yang dilakukan, untuk mencari nilai tahanan tegangan tembus per KV dapat dihitung dengan persamaan 2.2.

$$
\begin{aligned}
& R=\frac{s}{K V} \\
& \mathrm{R}=\frac{2,5 \mathrm{~mm}}{30,7}=0,0814 \mathrm{~mm} / \mathrm{KV}
\end{aligned}
$$

\subsubsection{Memebandingkan Nilai Tahanan Oli Tansformator Setelah Dilakukan Langkah Pemurnian Dengan Standart SPLN-IEC NO $196 \& 256$}

Setelah dilakukan pengukuran dan setelah dilihat dari standart yang berlaku yaitu standart SPLN-IEC NO 196\&256 nilai tahanan oli transformator sudah memenuhi standart, dan sudah bisa dioperasikan kembali seperti normal dan dapat dinyatakan keadaan oli dalam keadaan bagus. Dari nilai pengukuran yang dilakukan, untuk mencari nilai tahanan tegangan tembus per KV dapat dihitung dengan persamaan 2.2.

$$
R=\frac{\text { s dalam } m m}{\text { Udo dalam } K V}
$$


Sigma Teknika, Vol.1, No.2 : 122-132

November 2018

E-ISSN 2599-0616

P ISSN 2614-5979

$$
R=\frac{2,5 \mathrm{~mm}}{67,133}=0,0372 \mathrm{~mm} / \mathrm{KV}
$$

\subsection{Kesimpulan}

Setelah melakukan penelitian pengujian resistansi tegangan tembus pada oli transformator 5.000 KVA di PLTMG Panbil, dapat diambil beberapa kesimpulan, yaitu:

1. Nilai pengukuran tehanan tegangan tembus sebelum dilakukan pemurnian adalah sebesar 30,7KV/2,5mm, nilai tersebut sudah sangat mendekati standard SPLNMETHODE IEC no 196 \& 256, dimana standart oli transformator adalah senilai $30 \mathrm{KV} / 2,5 \mathrm{~mm}$ dan harus segera dilakukan pemurnian pada oli transformator tersebut.

2. Nilai pengukuran tahanan tegangan tembus oli transformator setelah dilakukan pemurnian adalah sebesar $61,133 \mathrm{KV} / 2,5 \mathrm{~mm}$, nilai oli transformator tersebut sudah layak dioperasikan kembali, karena sudah memenuhi standard setelah dilakukan pemurnian. Standard setelah dilakukan pemurnia adalah sebesar 50KV/2,5mm. Maka dari hasil itu, oli transformator sudah dinyatakan dalam keadaan bagus.

\subsection{SARAN}

Dalam melaksanakan penulisan tugas akhir di PT. Panbil Utilitas Sentosa Batam muka kuning. dari semua Bab-Bab yang telah ditulis, saran yang dapat penulis ambil adalah:

1. Perlu test temperature oli transformator, dimana kalau kita lakukan test temperature pada oli transformator, kita dapat mengetahui dititik berapa temperature oli transformator akan bekerja/memberi perintah pada transformator akan mati (trip).

2. Perlu test proteksi secara global setiap tahun, dimana bertujuan untuk mengetahui apakah ada komponen yang rusak atau sudah tidak bekerja sebagai mana mestinya.

\section{DAFTAR PUSTAKA}

1. Aslimeri. 2008. Teknik Transmisi Tenaga Listrik. Jakarta : Departemen Pendidikan Nasional.

2. Ghalia,1983. Teknik Tegangan Tinggi. Indonesia. Jakarta

3. Anonim. 1995. IEC-156. Breakdown Voltage at Power Frequency Tes Method

4. Bonggas L. Tobing. DasarDasar Teknik Pengujian Tegangan Tinggi. Indonesia. Jakarta. 